JOURNAL OF AL AZHAR UNIVERSITY ENGINEERING SECTOR

Vol. 13 , No. 48, July $2018,1118-1124$

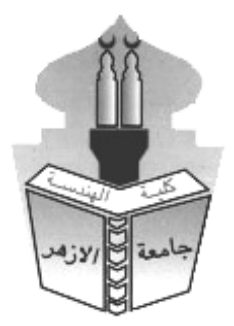

\title{
DESIGN AND PERFORMANCE OF HYBRID WIND-SOLAR ENERGY GENERATION SYSTEM FOR EFFICIENCY IMPROVEMENT
}

\author{
Salama Abu-Zaid Abo-Alela \\ Electrical Engineering Department, El-Azhar University, Cairo, Egypt. \\ E-mail: slama.abo@gmail.com
}

\begin{abstract}
Renewable energy sources have attracted wide attention due to their advantages of being abundant in nature and nearly non-polluting. Hybrid renewable energy system is the combination of two or more energy sources, one of the most feasible and reliable Grid connected renewable energy systems are the hybrid wind-solar sources. An optimization of hybrid wind-solar system is the process of selecting suitable components, design and control strategy to provide efficient, reliable and cost effective alternative energy. This paper presents the design of an optimized hybrid wind-solar energy system with high performance power generation of hybrid solar photovoltaic (PV) and a large capacity doubly fed induction generator (DFIG) based wind energy system. The proposed scheme uses both the grid side converter (GSC) and rotor-side converter (RSC) of DFIG to inject PV power to the grid. This proposed scheme provides an elegant and economic integration of PV source and DFIG-based wind energy source. The PV solar is connected directly to the dc-link. A nonlinear control is applied to extract Maximum Power from the PV under variable operating conditions. The proposed scheme does not hamper MPPT of PV and wind sources except during very rarely occurring environmental glitches, which the PV power control algorithm is suitably geared to handle using an artificial neural network (ANN).
\end{abstract}

\section{INTRODUCTION}

The renewable energy systems and especially wind energy generation and photovoltaic (PV) generation systems have attracted great interests in recent years [1]. PV energy appears quite attractive for electricity generation because of its noiseless, pollution-free, scale flexibility, and little maintenance [2]. It is global and can be harnessed without using rotational generators.

The most popular wind turbines generator is doubly fed induction generator (DFIG). It has converters rated at about $25 \%-30 \%$ of the generator rating. It also offers several advantages including four-quadrant active and reactive power capabilities [3], variable speed operation through the rotor side converter (RSC) and grid side converter (GSC) [4, 5]. Such system results in lower converter costs and lower power losses compared to a system based on a fully fed synchronous generator with full-rated converter. 


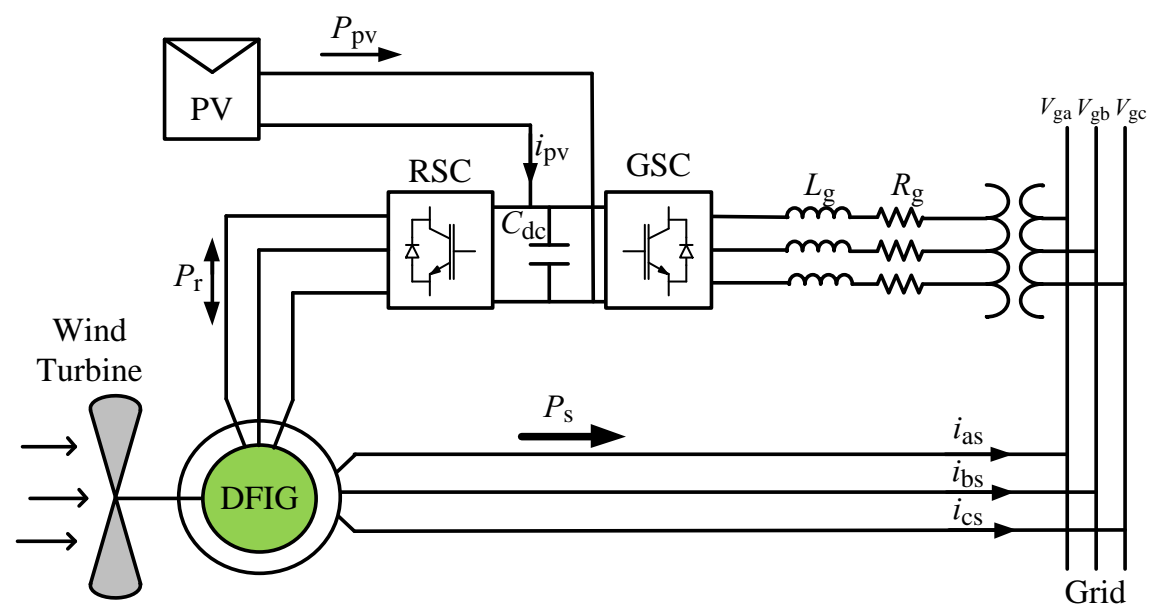

\section{THE PROPOSED HYBRID SYSTEM}

Fig. 1: The Proposed Solar PV-Wind Energy System Based DFIG.

The system advantages can $\mathrm{b}$

e summarized as follows:

Overall cost is reduced due to elimination of PV Inverter.

$>$ Optimization of the power converters utilization.

$>$ Reduction of the circulating power flow in the DFIG system. This cuts down the losses of the overall system, and enhances the overall system efficiency.

$>$ Realization of the Maximum extracted power from PV.

$>$ Controlling the pitch angle of the wind turbine to avoid.

$>$ Minimization of the grid-injected power Variation over a day.

$>$ The proposed configuration and control scheme provide an elegant and economic integration of PV source and DFIG-based wind energy source.

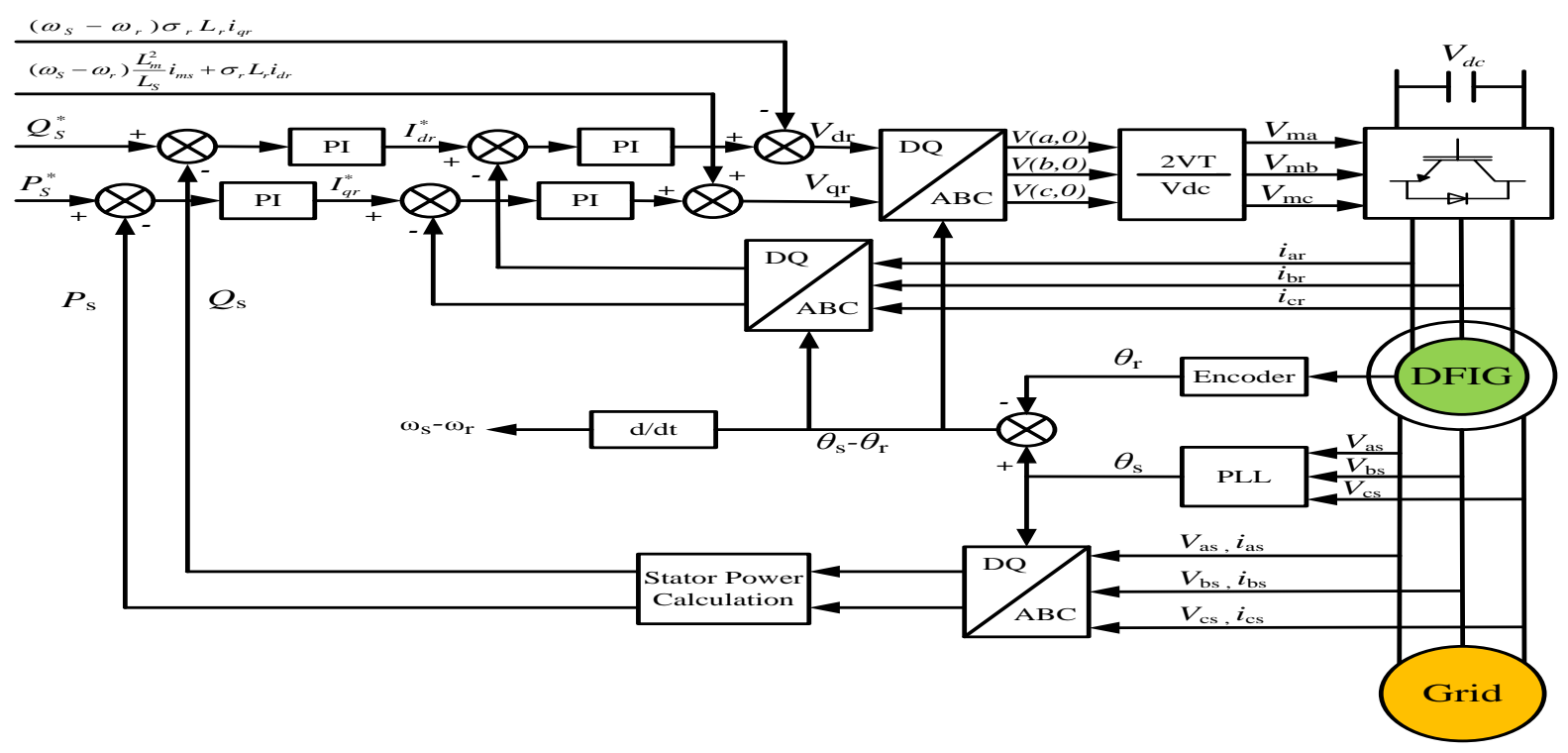

Fig. 2: Block Diagram For The Rotor-Side Converter Control.

\section{CONTROL SCHEME FOR ROTOR SIDE CONVERTER}

Figure 2 shows the overall vector control scheme of the RSC in which the independent control of the stator active power $P_{s}$ and reactive power $Q_{s}$ is achieved by means of rotor current regulation in a stator-flux-oriented synchronously rotating reference frame [6,7].

\section{CONTROL SCHEME FOR GRID-SIDE CONVERTER AND PV POWER}

In DFIG wind turbine, the GSC controls the dc-link voltage and contributes to the reactive power or grid voltage support control of the overall DFIG system as well [18]. In the d-q reference frame the GSC current model, is represented by: 
$L_{g} \frac{d i_{g d}}{d t}=-R_{g} i_{g d}+L_{g} w_{s} i_{g q}-\frac{V_{D C}}{2} m_{g d}+v_{g d}$

$L_{g} \frac{d i_{g q}}{d t}=-R_{g} i_{g q}-L_{g} w_{s} i_{g d}-\frac{V_{D C}}{2} m_{g q}+v_{g q}$

where $m_{g d}$ and $m_{g q}$ are the modulation indices.

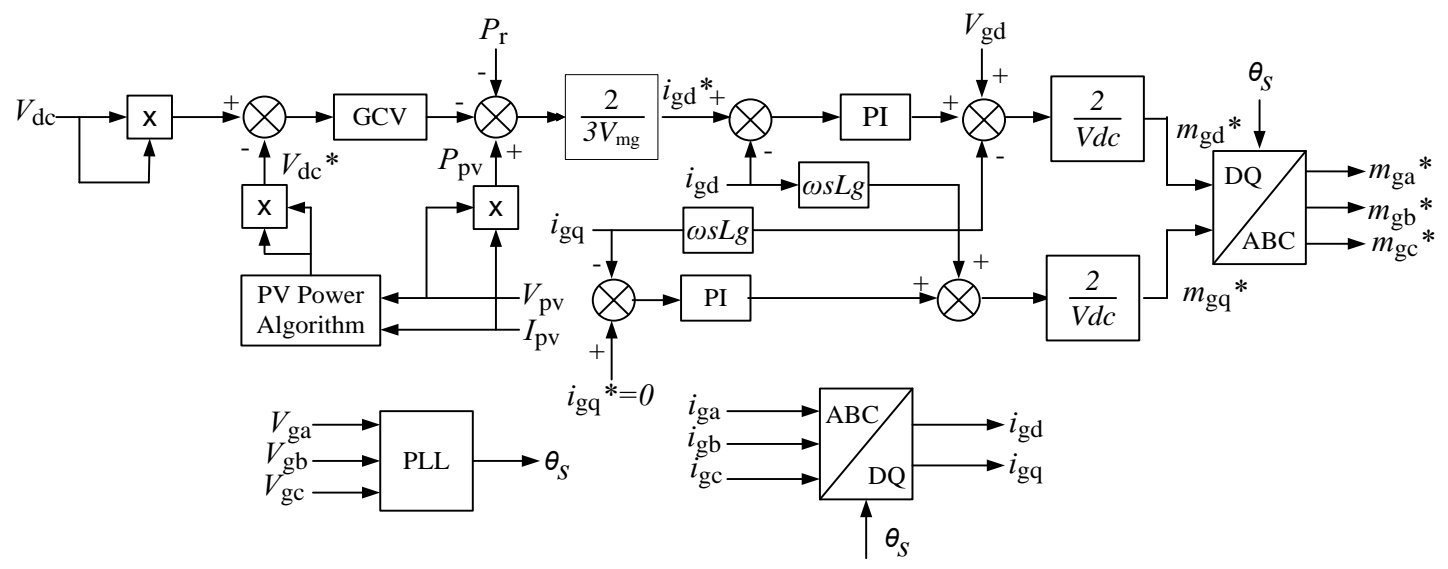

Fig. 3: Proposed Control Strategy For The Grid-Side Converter.

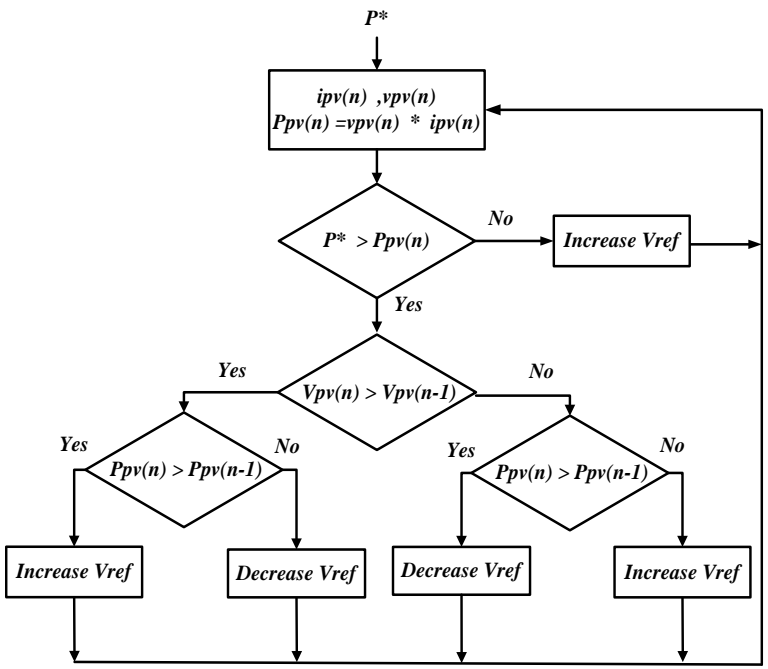

Fig.4: PV Power Control Algorithm for the Proposed Hybrid System.

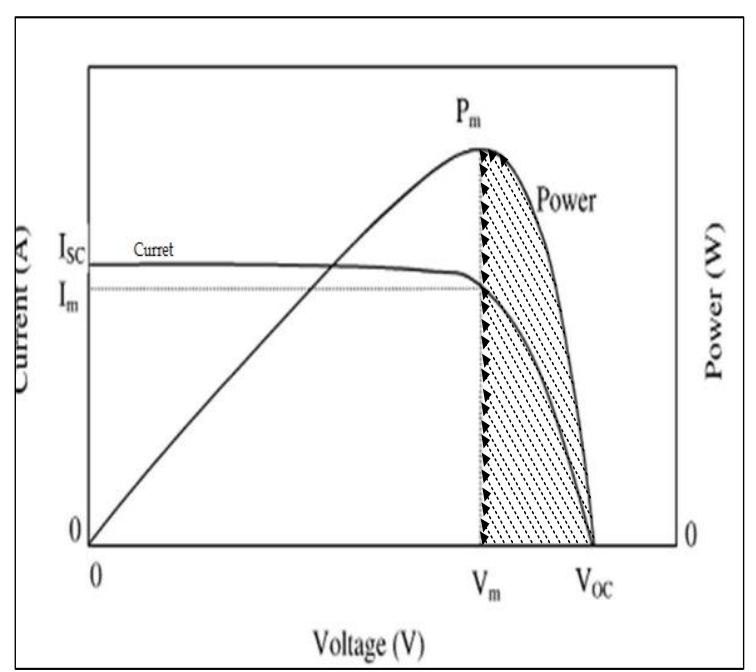

Fig. 5: The Controlled Operational Region for the PV System

me is aligned with the voltage vector, 1.e, $v_{q g}=0$. New variables $Y_{g d}$ and $Y_{g q}$ can be introduced in (33) and (34) to obtain the transfer function, $G_{i g}$ to enable the design of the inner current loops as follows: $\quad G_{i g}=\frac{I_{g d}(s)}{Y_{g d}(s)}=\frac{I_{g q}(s)}{Y_{g q}(s)}=\frac{1}{L_{g s}+R_{g}}$

From (33) and (34) the modulation indices $m_{g d}$ and $m_{g q}$ can be expressed as follows to incorporate decoupling and feed forward compensation: $\quad m_{g d}=\frac{-2}{V_{D C}}\left(y_{g d}-L_{g} w_{s} i_{g q}-v_{g d}\right)$

$$
m_{g q}=\frac{-2}{V_{D C}}\left(y_{g q}+L_{g} w_{s} i_{g d}\right)
$$

$G_{\text {cig }}$ is used to design the PI compensator for the inner current control loop of grid side converter. Thus, elements of $G_{\text {cig }}$ are:

$$
K_{\text {Pig }}=\frac{L_{g}}{T_{\text {cig }}} ; \quad(38)=\frac{R_{g}}{T_{\text {cig }}}
$$


Where $K_{\text {Pig }}$ and $K_{\text {Iig }}$ are the PI controller's proportional and integral parameters respectively. With the previous compensator parameters, the closed-loop transfer function of the current control loop GCL can be reduced to first order with unity gain as follows: $G_{C L}(s)=\frac{1}{T_{\text {eig }} S+1}$

Plant model for the PV terminal (dc link) voltage control can be determined from the power balance condition across the dc and ac ports of GSC as follows

$P_{p v}=\frac{d}{d t} \frac{1}{2} C_{D C} v_{D C}^{2}+P_{r}+\frac{3}{2} v_{g d} i_{g d}$

Assuming the inner current control loop of GSC to be considerably faster ( $T_{\text {cig }}$ is small), the reference, $i_{g d}^{*}$ is used as the controlling parameter for dc-bus voltage regulation. $V_{D C}^{2}$ is state as well as an output variable while $i_{g d}^{*}$ is the control variable and input to the inner current control loop. Using a new variable $\mathrm{p}_{\mathrm{h}}$, the transfer function $\mathrm{G}_{\mathrm{V}}$ can be written as follows:

$G_{V}(S)=\frac{V_{D C}^{n}(S)}{P_{h}(S)}=\frac{2}{C_{D C} S}$

Where $i_{d g}{ }^{*}$ is related to $\mathrm{p}_{\mathrm{h}}$ as follows:

$i_{g d}^{*}=\frac{2}{3 V_{g d}}\left(-p_{h}+P_{p V}-P_{r}\right)$

Rotor power $P_{r}$ and $\mathrm{PV}$-power $P_{P V}$ from measurement may be provided for feed-forward compensation to improve dynamic response against disturbances. The loss component of the converter and that of dc-link cannot be measured. Therefore, the integral term is added with a lead compensator to achieve zero steady-state error and sufficient phase margin. A phase boost ( $\emptyset_{\text {Boost }}$ ) at the required cut-off frequency (WCV) of the gain plot can be designed such that WCV $\approx 0.1$ to $0.3 \times 1 /$ Tcig. Thus, $\mathrm{G}_{\mathrm{CV}}$ has the following form: $G_{C V}(s)=\frac{h s+r / \alpha}{s}$

where $r=W C V \sqrt{\alpha}, \alpha=\frac{1+\sin \emptyset_{\text {Boost }}}{1-\sin \emptyset_{\text {Boost }}}$ and $h$ is adjusted such that the gain plot cuts the frequency axis at $W C V$. The GSC control strategy is shown in Fig. 3. The inner loop for grid-side current control and the outer loop for dc-link (PV terminal) voltage control.

$V_{D C}$ was assumed to be a constant for the design of inner current control. In the proposed scheme, PV power is controlled by regulating $V_{D C}$ and ensuring that the operation does not shift to the over modulation range. The PV power control algorithm for the proposed hybrid PV-wind system is illustrated in Fig. 4. Where, the reference power $\left(\mathrm{P}^{*}=P_{G S C}-P_{r}\right)$. The MPPT can be achieved for optimum power and also precise power control depending upon the operating mode, environmental conditions, and GSC loading. The shaded part in Fig. 5 shows the operation region for the PV system. This means when the wind speed increases over the rated value in the same time the irradiance is at its maximum value, the PV voltage is increased in order to shift the PV operating point shifts from MPP to avoid overloading of the grid side converter.

The GSC is an group of electronic switchs (IGBTs, SCR,....) that have a limtted overload capability. Thus, to improve the system response in the worest operational region (high wind speeds \& high irradiance), the non-linear characterestics of the PV panels is used to train an artificial nerural network (ANN) to control the DC-link voltage directly without any iterative solution.

The DC-link voltage can be predicted accurately from a given PV power using artificial intelligent. 


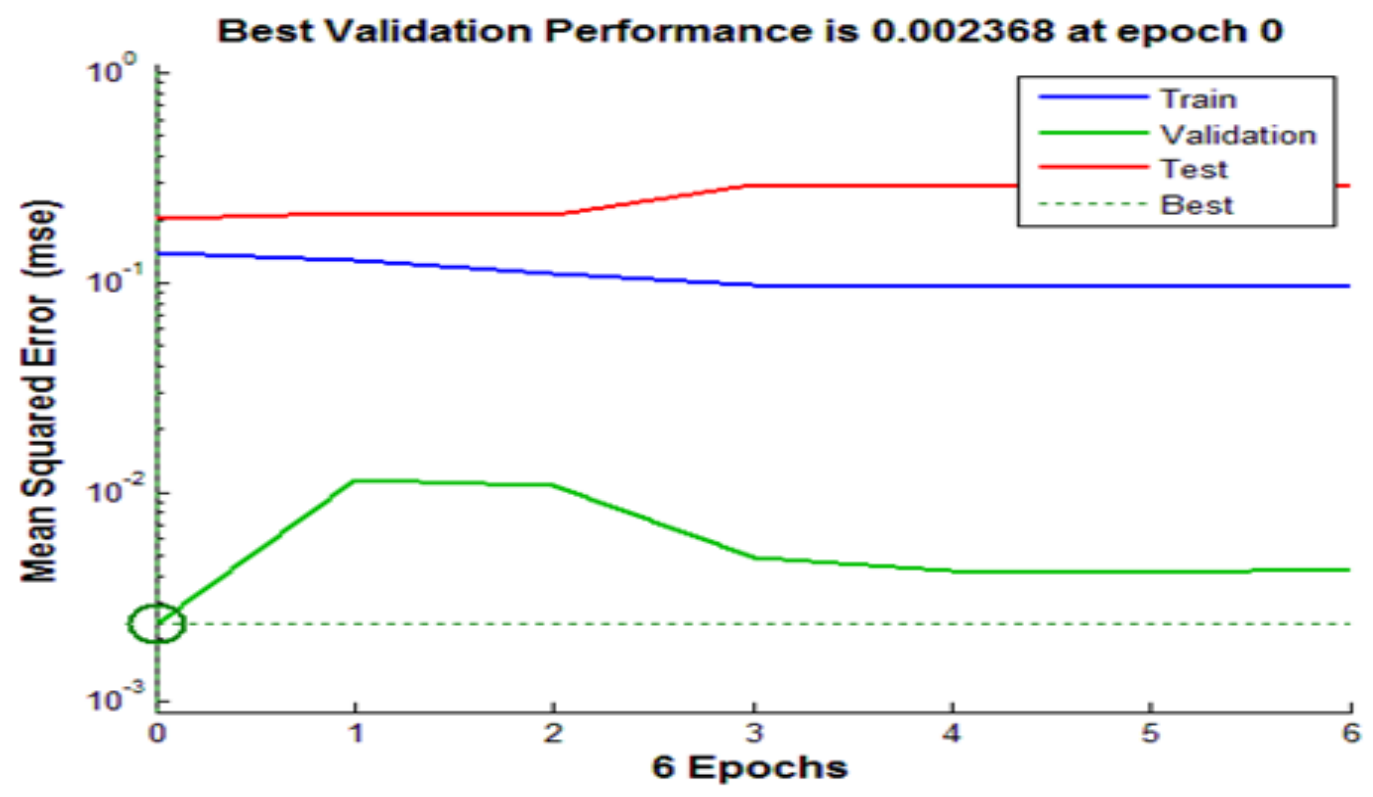

FIG. 6. PERFORMANCE OF TRAINING

The proposed control scheme for the GSC differs from the conventional control schemes in the following points:

A modified PV power control algorithm has been inserted in the control scheme presented for GSC in the proposed system, and not just a conventional MPPT control.

$>$ An additional control loop has been inserted to tackle the "worst case" environmental impact (high solar radiation and high wind speed existing at the same time) by automatically adjusting GSC loading.

$>$ The PV and the wind systems are designed to operate at MPP during most of the time. However, during a harsh sunny day and heavy wind conditions occurring simultaneously, the PV operating point shifts from MPP in order to avoid overloading of GSC.

The parameters of the hybrid system and the final form of controllers determined from the previous procedure are presented in appendix.

\section{SIMULATION RESULTS}

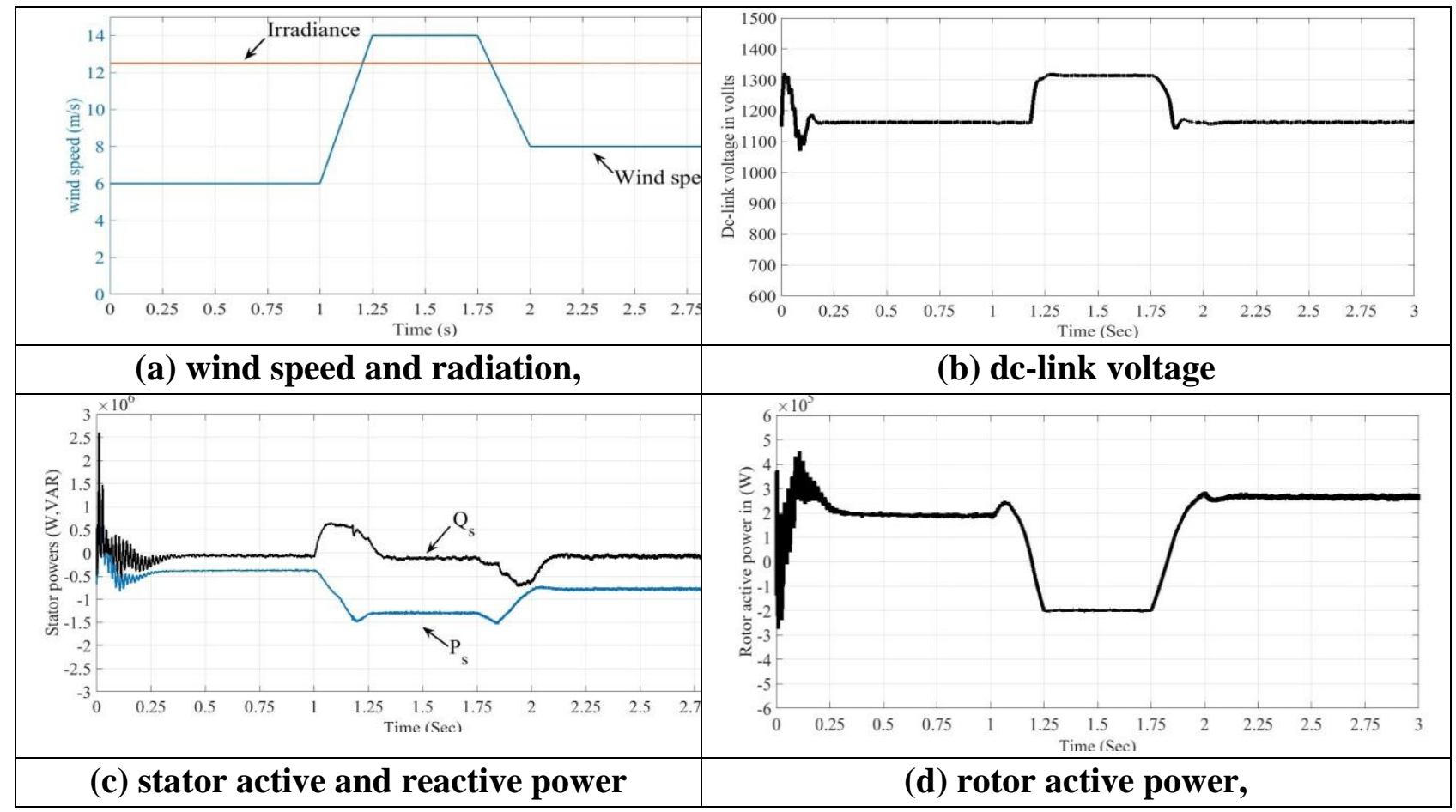




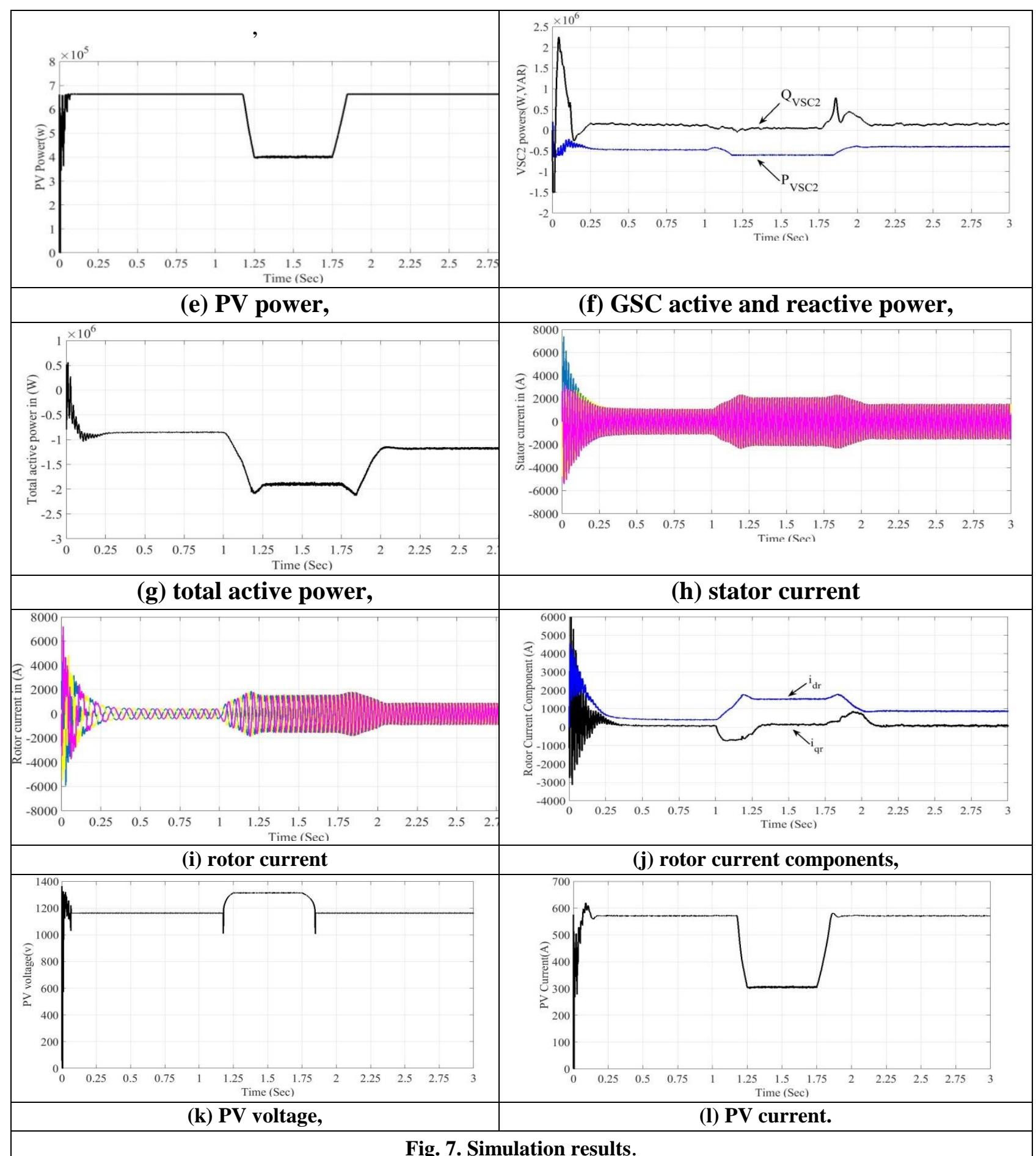

\section{CONCLUSION}

Fig. 7. Simulation results.

The hybrid system based DFIG variable speed wind and PV energy conversion system has been successfully developed to overcome several drawbacks of the individual PV and wind energy sources. This paper shows how the integrated GSC and RSC control is designed to implement the maximum power extraction, the dc-link voltage control, active and reactive power, and grid voltage support control functions. The hybrid system with MPPT has been implemented and simulated using MATLAB/ Simulink environment. The system has been tested for different wind speed and PV irradiations conditions. The simulation results have been analyzed, it is shown that the generation system will supply constant voltages with varying wind speed and irradiation. The PV and the wind systems operate at MPP during most of the time. Also results illustrate that the rotor active power varies under variable wind speed. In sub synchronous mode of operation, the rotor absorbed the active power from the 
grid or it absorbs a portion from the PV generated power. That in turn lowers the KVA rating of the GSC and also its cost. In super synchronous mode of operation, the rotor gives its power to the grid. This mode of operation happens at lower levels of solar irradiance. This in turn insures the overloading of GSC is mostly unexpected. At the worst cases of operation during a harsh sunny day and heavy wind conditions occurring simultaneously, the overloading of GSC can be controlled by reducing the PV generated power. The PV operating point shifts from MPP so as to avoid overloading of GSC. It's clear that the proposed system optimally making the best possible utilization of its converters and uses the daily available energy from solar and wind sources.

\section{REFERENCES}

[1] H. Xu, J. Hu and Y. He, "Operation of Wind-Turbine-Driven DFIG Systems under Distorted Grid Voltage Conditions: Analysis and Experimental Validations," IEEE Transactions on Power Electronics, Vol. 27, NO. 5, pp.2354-2366, May 2012.

[2] Krismadinata, N. Abd. Rahim, H. W. Ping, and J. Selvaraj, "Photovoltaic module modeling using Simulink/matlab," The 3rd International Conference on Sustainable Future for Human Security SUSTAIN 2012, pp.537-546, 2013.

[3] J. Yao, H. Li, Y. Liao, and Z. Chen, "An Improved Control Strategy of Limiting the DC-Link Voltage Fluctuation for a Doubly Fed Induction Wind Generator," IEEE Transactions on Power Electronics, Vol. 23, No. 3, pp. 1205-1213, May 2008.

[4] L. Xu, and P. Cartwright, "Direct Active and Reactive Power Control of DFIG for Wind Energy Generation," IEEE Transactions On Energy Conversion, Vol. 21, No. 3, pp. 750- 758, September 2006.

[5] H. Nian, and Y. Song, "Direct Power Control of Doubly Fed Induction Generator under Distorted Grid Voltage," IEEE Transactions on Power Electronics, Vol. 29, No. 2, pp. 1198 1208, February 2014.

[6] L. Qu, and W. Qiao, "Constant Power Control of DFIG Wind Turbines With Supercapacitor Energy Storage," IEEE Transactions on Industry Applications, Vol. 47, No. 1, pp. 359-367, February 2011.

[7] Ab. Hamadi, S. Rahmani, K. Addoweesh and K. Al-Haddad, "A Modeling And Control Of DFIG Wind And PV Solar Energy Source Generation Feeding Four Wire Isolated Load," 39th Annual Conference of the IEEE Industrial Electronics Society, IECON, pp. 447-451, November 2013. 